\title{
The Coexistence of Contradictory Properties in the Same Subject According to Aristotle
}

\author{
Lorenzo Peña \\ Spanish Institute of Advanced Study [CSIC], Madrid
}

published in Apeiron 32/3

(Academic Printing and Publishing, University of Alberta, Edmonton, Canada, 1999), pp. 203-30 ISSN 0003-6390

1.- General Overview

Contents:

2.- A Detailed Analysis of the Anti-Contradictorialist Reasoning in Book IV

3.- Aristotle's Quandary Concerning Degrees and Intermediaries

4.- Rejection and Denial; Admissible vs Inadmissible Contradictions

\section{§1.- General Overview}

A continuous if rather winding thread in Aristotle's fairly complex argument in Metaphysics $\Gamma$ against the assertion of any contradiction is that he who asserts a contradiction is thereby committed to a rejection of degrees. On the other hand, though, Aristotle claims that there can be no intermediary situation inbetween pure or entire truth or existence and utter, complete falseness or nonexistence. Unfortunately though such a combination of views can be rendered noncontradictory at best through manoeuvres he himself rejects.

That the assertion of a contradiction entails the rejection of degree variations is arguedfor in a roundabout, muddy way (1008a30-1008b31). The gist of the argument is as follows.

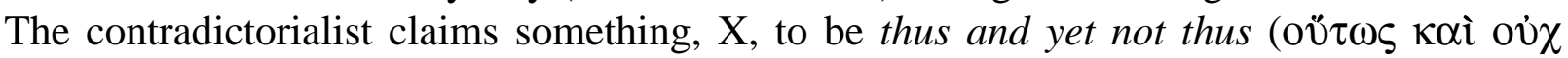
ov̈ $\tau \omega \varsigma), A$ and not-A. He is thereby committed to the view that something is neither so nor not-so, neither A nor not-A, thereby renouncing the principle of excluded middle. So, he drops the customary view that $\mathrm{X}$ either is A or else is not A. Now, if the thus dropped view is wrong or less correct than the contradictorialist view - namely that X is A and not- $\mathrm{A}$-, then the contradictorialist himself must admit that some claims are completely false, among others the claim that it is no more true to say that $\mathrm{X}$ is $\mathrm{A}$ and not- $\mathrm{A}$ than to say that $\mathrm{X}$ is either A or not-A; hence he himself must reject some contradictions. If he does not, differences of degree vanish. Thus an out and out contradictorialist does away with degrees.

The argument now proceeds as follows (1008b31-1009a5). There are degrees of truth. The more thus-and-so something is, the closer it is to what is thus-and-so. Therefore something must be purely, unpollutedly thus and so; something must be purely true. But even if that conclusion does not follow - he goes on to argue - , some assertions are truer than others, and accordingly not all are equally true; hence not all contradictions are true.

Apparently Aristotle has (at most) managed to prove that not all contradictions are true, or - alternatively put — that it is irrational to espouse all contradictions. But is he pursuing 
a mere discussion with a particular philosopher - e.g. Heraclitus? ${ }^{1}$ He seems not. Despite his targeting Heraclitus - as well as Democritus, Anaxagoras, ${ }^{2}$ Empedocles and others as people having espoused the view that there are contradictory truths, he obviously wants to establish, in a general way, that any such view is wrong and irrational. Yet, whatever Heraclitus' or other presocratic philosophers' particular opinions, the mere assertion of a contradictorialist thesis - to the effect that a certain contradiction is true - does not amount at all to the claim that every contradiction is true.

But Aristotle seems to assume that, if the claim that all contradictions are true is to be rejected, so is the that claim some contradictions are true. Why? Most likely on account of the principle of logical equity (to treat like cases alike.) ${ }^{3}$

Thus, Aristotle resorts to the existence of degrees as a safe shield against the contradictorialist. He goes as far as to accept - as a partial concession to the contradictorialist - that two contrary properties can be both present in the same object $\pi \hat{n}$ (which is often translated as 'in some way or other' or 'somehow', but which in this context [1011b22] could perhaps be read as 'to some extent').

\footnotetext{
1. Among the vast amount of literature on Heraclitean exegesis Barnes's discussion is, as always, one of the things to seriously and attentively read (see The presocratic philosophers, ed. by T. Honderich, rev. ed. 1982, Routledge, pp. 70-1). Barnes carefully distinguishes a number of different theses which can be attributed to Heraclitus, such as — letting « «'» mark a predicate contrary to « $\phi »-:(H 1)\left\ulcorner\forall \phi \exists x\left(\phi x \& \phi^{\prime} x\right)\right)^{\urcorner} ;(\mathrm{H} 2)$ $\left\ulcorner\forall x \exists \phi\left(\phi x \& \phi^{\prime} x\right)\right\urcorner ;(H 3)\left\ulcorner\forall \phi\left(\phi=\phi^{\prime}\right)\right\urcorner$. Sextus Empiricus and many others attribute either (H1) or (H2) (or both) to Heraclitus (“opposites belong to the save thing" - Pyrr. Hyp. I.210, II.63). Barnes is right to argue that there is a world of difference between (H1) or (H2), on the one hand, and $(\mathrm{H} 3)$ on the other. Even if a thing can be both wet and dry (each to some extent), that does not nullify the difference between dryness and wetness. If we represent as « $p \leftrightarrow q$ » sameness of degree-realization between the fact that $p$ and the fact that $q$, surely (H3) would require something like this: $\left\ulcorner\forall \phi \square \forall x\left(\phi x \leftrightarrow \phi^{\prime} x\right)\right\urcorner$, which Heraclitus does not seem to have advocated. He may have said something which is translated as (H3), but what he probably meant is $(\mathrm{H} 1)$ or $(\mathrm{H} 2)$, from both of which a weaker and more plausible contention follows, namely $(\mathrm{H} 4)$ : $\left.{ }^{\circ} \exists x \exists \phi\left(\phi x \& \phi^{\prime} \mathrm{x}\right)\right\urcorner$. See also G.S. Kirk, J.E. Raven \& M. Schofield, The Presocratic Philosophers, 2d. ed., Cambridge U.P., 1983, pp. 186ff. Those authors plausibly claim (p.186) that «by 'the same' Heraclitus evidently meant not 'identical' so much as 'not essentially distinct'», or (p.189) 'essentially connected'. Finally let me mention Charles H. Kahn's authoritative aprioristic construal (The Art and Thought of Heraclitus, Cambridge U.P., 1979, pp. 270-1), according to which Heraclitus cannot possibly have meant what he literally said (not even ( $\mathrm{H} 4)$, since it would be «incoherent or irrational»); hence «[T]he need for a two-tongued statement is a consequence of the epistemic deafness of his audience». What one wonders is if, with such an overcaritative hermeneutic approach, Heraclitus - or any other philosopher for that matter — had any particular philosophical thing to say.
}

2. On Anaxagoras' views see Barnes, op. cit, pp. 320-1, 441ff. Barnes argues that, unlike Democritus - who purportedly is entitled to shirk contradictions by devising a duality of senses of the verb 'exist', 'exist,' and 'exist,' - neither Anaxagoras nor Empedocles can accept the existence of men or clouds, or of anything which comes to be or passes away. What has not occurred to Barnes is the possibility of degrees of existence. The initially thoroughly blended stuff in Anaxagorean cosmology can be thought to have, in some degree, contained everything which later on comes to be - i.e. increases its degree of reality. Surely that their views entailed the acceptance of true contradictions did not scare Democritus, Anaxagoras or Empedocles - let alone Heraclitus. They needn't wait for paraconsistent logic (logic as logica docens) to arise some 25 centuries later. Their underlying logica utens was already paraconsistent. See also, on Anaxagoras, Kirk, Raven \& Schofield, op. cit., pp. 352ff.

${ }^{3}$. The principle of logical equity or fairness is plainly not an infallible ontological principle but provides rather a somewhat vague rule of thumb (it is not quite clear when two situations are relevantly alike). However it can be thought to be a plausible principle, to be safely used in «dialectical» argumentations - in the Aristotelian sense, i.e. in the kind of non-strictly demonstrative arguments gone into in Topics. In Soph. El. 17 (175a 32-7) Aristotle claims that, when we have to fight against contentious arguers, i.e. when we are warranted to remark that they are not really arguing a case, we may — and indeed ought to — resort to plausible refutations and solutions. The Heraclitizer is surely - according to Aristotle - not arguing soundly or indeed proposing a defensible view. (See Metaph. IV, 3: 1005b25-30: what he says he cannot believe, since to believe that a contradiction is true would entail to have mutually contradictory thoughts - that $p$ and that not- $p-$, and to have the thought that not- $p$ means [or implies] to not-have the thought that $p$; Aristotle seems - as happens often to him - to suffer from a confusion concerning the scope of negation, owing to some idiomatic particularities of Greek.) While engaging in a refutation of the Heraclitizer's views, or alleged views, less than absolutely certain principles must be allowed to feature as premises or assumptions. 
However, upon granting such a concession, Aristotle goes on to attack the idea that inbetween assertion and denial, truth and falseness, there is some intermediary tertium quid. The would-be halfway entity or situation - he replies - , lying inbetween truth and falseness or existence and nonexistence, would have either a quite heterogeneous nature or else the same nature as one of the opposite extremes but in a diminished degree. The problem - says Aristotle [1012a1] — is that such a kind of inbetweenness is not to be seen. In other words, although something can be somehow or somewhat so and yet also somehow or somewhat not-so, that situation is not to be regarded as one of lying inbetween being-so and not-being-so — in any sense. Otherwise (1012a3ff.) every contradiction would admit of a $\mu \varepsilon \tau \alpha \xi \tilde{v}$, something inbetween, an intermediary situation - even the clearest all-or-nothing alternatives, such as oddness and evenness.

The underlying reasoning seems to be again that (in virtue of the principle of logical equity), unless the very nature of the contradiction, the mere fact that the contradictory terms are contradictory, is enough to prevent the arising of intermediaries, nothing can - not even the peculiar characteristics of such or such a pair of opposites.

Then (1012a12) an infinite regress would be triggered: there would be an intermediary situation between one of the extreme opposites and the intermediary situation and so forth. Positing intermediaries between existence and nonexistence, or truth and falseness - as Anaxagoras is reported to have done - is thus tantamount (1012a25-27) to espousing Heraclitus' view that there are true contradictions.

Is Aristotle's whole doctrine on the matter contradictionless? In order to keep clear of contradictions such a doctrine must embrace the view that only what is so or so to the utmost is so or so tout court (alethic maximalism). One of the results of such a view is that being-to-this-or-that-extent-so is really quite unlike being-so. For what is to some extent (only) thus-or-so cannot truthfully be said to be thus-or-so at all. Thus Aristotle himself is committed to a view he tries to eschew and reject, namely that the intermediary situation is something entirely and irreducibly different as regards both extremes.

In a few exceptional passages Aristotle uncharactersctristically verges on accepting that an intermediary situation is a mixture of the two extreme opposites and that both opposites are present in such a situation - that they coexist. He then seems tempted to concede the

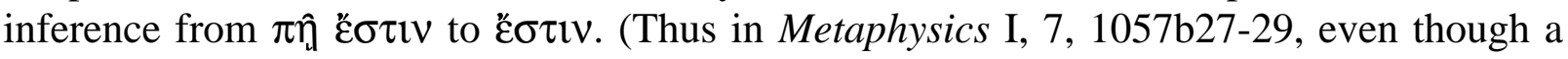
' $\pi \omega \varsigma$ ', or 'somehow' softens the claim.) Similar views are encountered elsewhere.

Yet, Aristotle's main idea about the nature of contradiction prevents him from seriously countenancing such a mixture approach. Since contrariety takes place according to form, and forms do not admit of lessening, neither can they mix with their respective opposites; accordingly the blending or mingling view of intermediaries has to be rejected in the end from an Aristotelian viewpoint. Thus the Stagirite leaves us with no coherent account of intermediaries. ${ }^{4}$

\footnotetext{
4. Aristotle finds fault with the mingling ontology Anaxagoras advocates because: either (1) that ontology contends that the ingredients remain in existence within the mixture, owing to which the mixture partly has the characteristic features of one of the ingredients, partly those of another ingredient, and thus, as a whole, and, all things considered, the blended stuff has contradictory properties; or else (2) the ingredients do not remain in existence in the resulting mixture, which accordingly has none of those features. In the former case, we are licensing a negation of the principle of noncontradiction, in the latter a negation of the principle of excluded middle - which again entails a negation of noncontradiction.

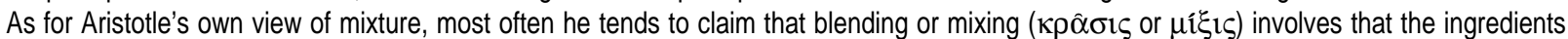
are not preserved, not even in small particles, since that would be composition rather than mingling; if mixing has taken place, the mixture ought
} 
Moreover - as we have pointed out - the existence of intermediaries between

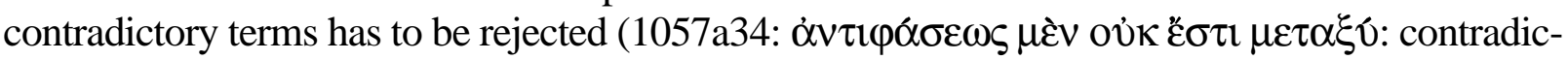
tories do not admit of intermediaries). Even though there is an intermediary inbetween black and white, there is none inbetween black and non-black. Aristotle is clearly telling us that, whenever a thing is not entirely black, it is not black, and likewise, when it is not fully white, it is not white. Grey things can neither be truthfully said to be white, nor black. Grey things are entirely and absolutely nonwhite, entirely and absolutely nonblack. Intermediaries between black and white are «intermediary» or «inbetween» only in a peculiar sense, as a tree is inbetween a hand and a hat (since it is neither). Those «intermediary» colours have no blackness and no whiteness at all; they are colours which are qualitatively irreducible, which are not mixtures of the mutually contrary colours black and white. (The opposition between blackness and whiteness is no lesser or milder than that between blackness and non-blackness.) ${ }^{5}$

Aristotle tries to avoid catastrophe by whittling down the range of predicates or properties admitting of degrees. Only certain subclasses of a few categories, such as quality, are, in principle, liable to come in degrees. Substances or essences cannot. ${ }^{6}$

This and other precautions seem to be of no avail. The whole framework of his views on whether opposite properties can coexist or not seems to contain contradictions.

It is ironic that the most outstanding argument against the acceptance of true contradictions in the history of philosophy lead the philosopher who developed it to a gradualistic contention that, in the end, besides clashing with his main assumptions, would - if seriously pursued - countenance the coexistence of contradictory properties in the same subject — and thus the truth of some contradictions. ${ }^{7}$

\footnotetext{
to be uniform throughout, each part of what is blended must be of the same kind as the whole stuff resulting from the mixing process. Aristotle distinguishes blending from dissolving: a drop of wine does not mix with a large volume of water, but rather it becomes water, a part of the whole mass of water. But when there is a certain balance in the resulting mass ( $\delta \tau \alpha \nu i \sigma \alpha \zeta \eta n \pi \omega \varsigma)$, then the admixture produces a new entity, while the ingredients are no longer there in actuality (Gen. et Corr. 1, 10: 328a27-33). In particular a mixture of two contraries is something $\mu \varepsilon \tau \alpha$

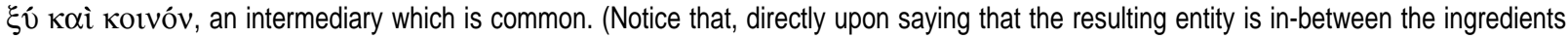
and common [to them] - in some sense - Aristotle remarks that contraries can be ingredients of a mixture.) Thus, even if the Stagirite rejects the Anaxagorean doctrine of universal mingling of all stuffs, he is not rid of the difficulties surrounding the account of mixtures. He is committed to the view that for a measure $\mathbf{M}_{1}$ there is a measure $\mathbf{M}_{2}$ such that an $\mathbf{M}_{2}$ mass of wine spilled over an $\mathbf{M}_{1}$ mass of water transforms both ingredients into a new liquid, while one single drop less of the spilled liquid would transform the wine into water. What if we dribble the mass of wine over that of water little by little? Aristotle would have us believe that the successively percolated drops become water one by one, and so the whole mass of wine is transmuted into water.
}

5. Although such is the prevailing doctrine Aristotle espouses - or at least is clearly committed to - , sometimes he grants that an intermediary ( $\mu \varepsilon \tau \alpha \xi \delta)$ plays the role of a contrary to each of the opposite properties, since the intermediary is somehow (or somewhat) both extremes at

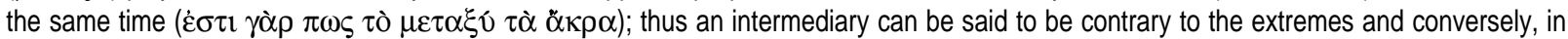

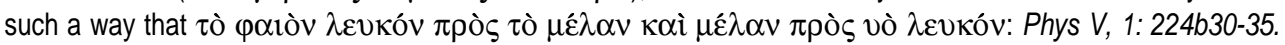

6. Substances do not admit of degrees (Cat:: $34 \mathrm{ff})$; e.g. this man is not more man than that man, nor can he become more, or less, man than he was.

7. In Cat. 6 (5b37-6a11) Aristotle argues that, were smallness and largeness qualities - which according to him they are not -, one same entity would be small as compared with another and large as compared with a third thing. Thus two contrary (putative) properties, smallness

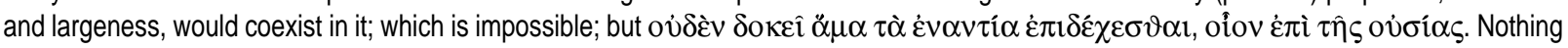
can be healthy and ill, or black and white, at the same time. It did not occur to Aristotle that, arguing in exactly the same way, no predicate admitting of degrees, of 'more' or 'less', would denote a quality. He himself claims that some things are hot for being cold, or cold for being hot. 


\section{§2.- A Detailed Analysis of the Anti-Contradictorialist Reasoning in Book IV}

We take as our main source the text Aristotle devotes to discussing the principle of noncontradiction in Metaphysics, Book IV, 1007b18 - 1012a28.

I am going to focus my attention on the relationship between the principle of noncontradiction and the principle of excluded middle, as well as on the possibility of degrees of truth, which seem to call for something in between (pure) truth and (pure) falsity, and hence to challenge the principle of excluded middle - at least as Aristotle conceives it.

The starting point in $1007 \mathrm{~b} 18$ seems to be altogether too modest. Aristotle seems content to defend a very unobtrusive, uncontentious view, namely that not all contradictions are true. What he is attacking to start with is the claim that $\dot{\alpha} \lambda \eta \vartheta \varepsilon i \varsigma \alpha i \dot{\alpha} v \tau \imath \varphi \alpha ́ \alpha \sigma \varepsilon 1 \varsigma \ddot{\alpha} \mu \alpha$ $\kappa \alpha \tau \grave{\alpha} \tau o \hat{v} \alpha \hat{v} \tau o \hat{v} \pi \hat{\alpha} \sigma \alpha$, i.e. that all contradictions about the same entity are true together (or at the same time). Let us call such a claim the Antiphantic Principle, or AP for short.

AP is not clearly ascribed by Aristotle to any philosopher, but the context clearly suggests he is fathering it on several philosophers, such as Heraclitus, Protagoras and Anaxagoras. Directly after stating AP he goes on to argue that it cannot be seriously maintained, and that what would follow would be a world like the one Anaxagoras depicts, wherein everything contains everything, or every stuff is a mixture of all staffs, and thus all things lie together. ${ }^{8}$ At the end of the passage, Anaxagoras is again taken to task as the main culprit, and his ontology is charged with a denial of the principle of excluded middle. The gist of Aristotle's proof is that denying noncontradiction and denying excluded middle are equivalent, and that the only apparently reasonable ground for such a denial is the one put forward by Anaxagoras, namely the existence of intermediary situations in between the extremes of pure, unmixed truth and sheer, unalloyed falsity; but that, upon reflection, such intermediary situations either cannot be countenanced or anyway do not fall afoul of the principle of excluded middle. ${ }^{9}$

Aristotle tries first to prove that $\mathbf{A P}$ entails that all things are one and the same. The proof is unperspicuous and its interpretation demands some guesswork as to the thread of the deduction.

First of all, what exactly is AP assumed to mean? Is 'the same entity' meant to be an implicit universal or an existential quantifier? In other words, is Aristotle discussing the view that all contradictions about all things are simultaneously true or is he challenging the

\footnotetext{
8. Aristotle repeats his argument against Anaxagoras' mixing cosmology in Gen. et Cor. 2,7 (334b4-8). The thoroughly mixed (or blended) pristine stuff Anaxagoras imagines would be neither water nor air nor fire nor earth nor anything; neither cold nor hot, nor ... Thus it would be Aristotelian prime matter - which cannot exist in actuality, only in potency. The Aristotelian solution of devising the dichotomy actuality/potency aims at avoiding Anaxagorean contradictions, Unfortunately it is fraught with difficulties of its own, besides being implausible, whereas Anaxagorean blending of stuffs, each endowed with an inner definite feature, is far more credible.

9. In Gen. et Corr. 2,7 (334b8-14) Aristotle envisages a solution to the problem of the blending of contrary predicates and stuffs (and he grants that earth is contrary to water, and air contrary to fire [335a4-6] - since each of them necessarily has a feature its contrary lacks, e.g. solidity as against fluidity, or coldness as against heat). The solution consists in claiming that, when one of two contraries, $A$, is actually present in one subject, $X$, the other, $B$, is there only in potency, but when neither completely exists ( $0 \tau \alpha \nu \mu \eta \eta \eta \alpha \nu \tau \lambda \varepsilon \lambda \omega \varsigma \dot{\varepsilon} \sigma \tau \imath$ ) in $X$, but $X$ is $A$ for a $B$ and

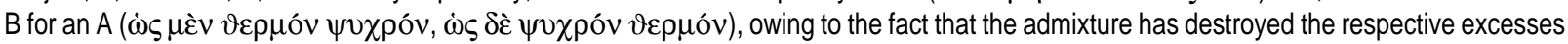

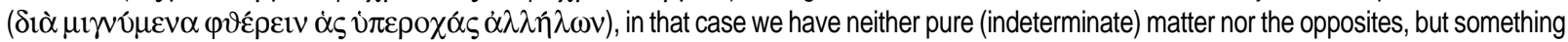
in-between $(\mu \varepsilon \tau \alpha \xi \delta)$. He proceeds to emphasize that the mean has considerable extension - i.e. that many or most things lie in-between the extremes (334b27-29).
} 
weaker claim that all contradictions about a certain, particular entity, $X$, are true? The former construal would of course make the discussion much easier for Aristotle to secure his case, but at the price of targeting a possibly nonexistent contender - or anyway one who espouses an exceedingly strong and unpalatable claim. Moreover, the ensuing discussion makes it clear that Aristotle is in fact challenging the view that all contradictions are true about X.

Aristotle resorts to several assumptions in order to show that, if all contradictions about $X$ are true, all things are one and the same. The first principle is that, if an entity, $X$,

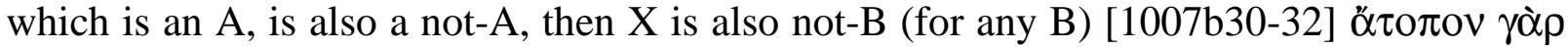

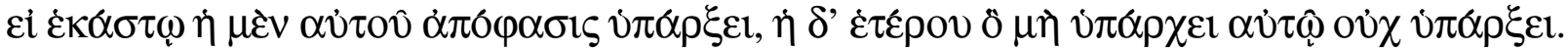
The verb ' $v \pi \alpha \rho \chi \varepsilon \imath v$ ' matters, since it is meaning the existence of a property or determination (be it a quality or an essential feature) in a subject. And what is conveyed by the sentence is that, when a determination $\mathrm{D}$ is present in a subject, and so is its negation - i.e. another determination, $\mathrm{N}$, contrary to $\mathrm{D}-$, then all negations of other properties are also present in that subject. Let us call such a principle the principle of negation, or PN for short. The rationale - which is not stated by Aristotle — seems to be that, if the presence of D in X does not stand in the way of not-D also entering $X$, then $X$ is open for every negative property to affect it. If a man's being a man is not enough to bar his being a non-man also, a fortiori he can also be a non-god, non-ship etc. For the only impediment for his being a non-man one can conceive is that he is a man. If that is not enough, nothing is, and so nothing will thwart his also being a non-Y, for every property Y. (1007b35-10008a1: $\varepsilon \dot{i} \delta \varepsilon \bar{\varepsilon} \mu \eta \dot{~} \dot{\pi} \alpha \rho \chi \varepsilon 1$

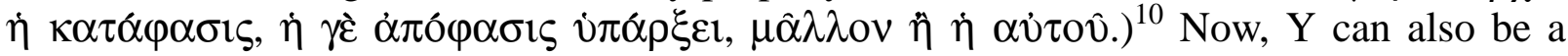
negative property; hence (1008a4) X will have all properties. (Clearly enough Aristotle is assuming the involutivity of negation: if $\mathrm{X}$ is a non-non-ship, $\mathrm{X}$ is a ship. $)^{11}$

That apparently settles the issue and Aristotle seems to believe he has won his first battle, by proving that $\mathrm{X}$ is then bound to be identical to anything and everything. Even so, the desired result — namely that all things are one — would require at least a further premise, or principle, such as reflexivity of identity.

However to say the truth Aristotle has not even proved that, upon assuming that all contradictions about $\mathrm{X}$ are true, $\mathrm{X}$ is identical to every entity. In order to reach such a conclusion he needs to assume that identity-attributions are among the meaningful predicates which can be both ascribed to and denied of X. And an advocate of AP may question the meaningfulness of identity-ascriptions. In any case, Aristotle falls short of bringing them out. Now is it entirely clear that he would countenance predicates such as 'being Socrates', 'being Athens' etc.?

Thus we have pinned down the following assumptions: PN; that negative determinations are determinations; involutivity; that identity-ascriptions are legitimate predicates; and the reflexivity of identity. Once all that has been granted, Aristotle may be said to have proved

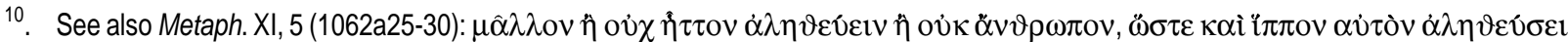

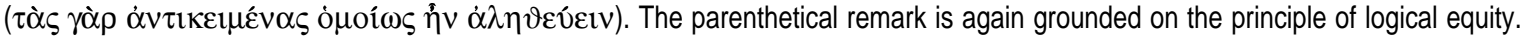

11. PN is looked upon by Aristotle as a corollary of the principle of logical equity. Those principles are formulated by Aristotle in Topics II, 10 (114b25ff); in particular PN: if out of two negative predicates, the one which is less likely to apply to a subject applies to it, so does the other. Aristotle develops a number of formulations and variants - upon plausible assumptions. Any of those variants can be used by Aristotle to implement a variant of the same argument: if an $A$ is not- $A$, then a fortiori it is not- $B$, for any «B».
} 
that if all contradictions about $\mathrm{X}$ are true, all things are but one (i.e. that a Parmenidean ontology can be reached by a path opposite to Parmenides' own way, since the Eleatic philosopher abhorred contradiction).

Second, Aristotle undertakes to show that AP entails that we are not bound to either assert or deny. In other words, the view under challenge entails a negation of the principle

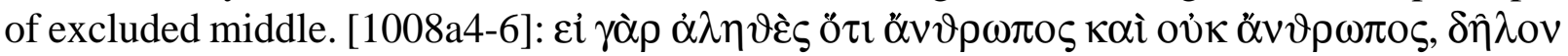

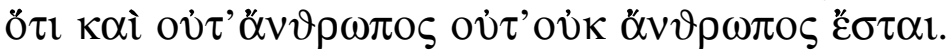

The ensuing discussion makes it abundantly clear that Aristotle is taking for granted that a composite negation amounts to an ascription of the doubly-negated predicate (involutivity): if $X$ is both man and non-man, $X$ is both non-non-man and non-man, hence $X$ is neither man nor not-man.

Since the proof is straightforward, one wonders why Aristotle is still needing the starting hypothesis AP. In fact he could quite easily rest his case now on a very modest hypothesis, namely that for some predicate, Z (say 'man'), and some particular entity, X, $\mathrm{X}$ is both $\mathrm{Z}$ and not-Z; whence it follows that $\mathrm{X}$ is neither $\mathrm{Z}$ nor not $\mathrm{Z}$. Probably, though, AP is still needed or wanted in order to generalize: if, for every predicate $Z, X$ is both $Z$ and not-Z, then for every predicate $\mathrm{Z} \mathrm{X}$ neither is $\mathrm{Z}$ nor fails to be $\mathrm{Z}$; thus $\mathrm{X}$ is proved to be utterly indeterminate.

The sequel of the argument (1008a11ff) shows that Aristotle remains overly concerned about the claim that all contradictions are true, and — for the time being — is content with challenging such a view. The advocate of $\mathbf{A P}$ is committed, not to a local, exceptional denial of a single instance of the principle of excluded middle (not to the claim that, for some particular predicate $\mathrm{Z}, \mathrm{X}$ neither is nor fails to be a Z) but to a stronger and more untoward view, namely that $X$ lacks all predicates.

In 1008a10-13 Aristotle grants for the first time that his adversary may be claiming something weaker than AP, namely that about $\mathrm{X}$ some contradictions are true but not all.

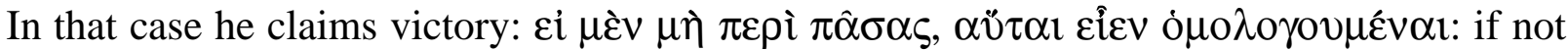
all contradiction are true [about X], then on that point at least we are allowed to agree; namely that Heraclitus and Anaxagoras were wrong and that there are pairs of contradictory predicates, «Z» and «not-Z», such that $\mathrm{X}$ can be ascribed either but not both.

However Aristotle has of course embarked upon a much more ambitious venture, namely that of proving that all contradictions are entirely false and must be utterly rejected. The line of argument from his provisional victory to the complete rout of any even partially contradictorialist claim is not always perspicuous.

Since the reasoning path is pretty roundabout and often convoluted, we must not be astonished to find at this point in the general argument a conclusion we were supposed

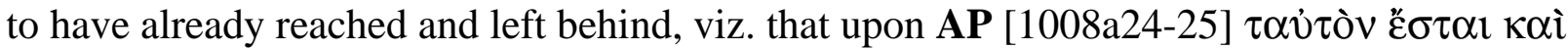

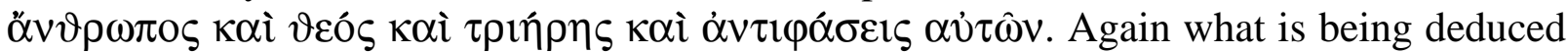
from the contradictorialist hypothesis is the Parmenidean claim that only one entity exists. That Aristotle is supposed to have already established. But now (in a parenthetical remark 10008a25-27) he is clearly arguing in a different way. First, he is assuming that, if $X$ is like that, so is any other entity. Then he assumes the principle of identity of indiscernibles. In order for the principle of identity of indiscernibles to operate, it must be applied to at least 
«two» putative entities, $\mathrm{X}$ and $\mathrm{Y}$. This is why Aristotle is clearly assuming that, once [all] contradictions have been ascribed to $X$, nothing stands in the way of ascribing all contradictions to $\mathrm{Y}$, be $\mathrm{Y}$ what it may.

Since that step is a momentous one, Aristotle had better clarify what is going on, which he does not. Clearly from X being man, god, ship etc. it does not follow — without further ado - that as much happens to everything. Yet Aristotle admittedly expresses a

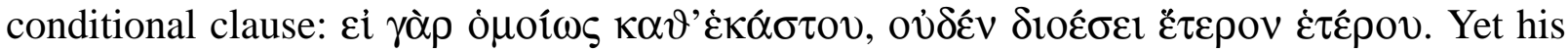
intention does not seem to be to merely show that at least one entity is such that not all contradictions are true about it. That meagre harvest would not be worth the strenuous effort. No, he is definitely after something stronger and more thoroughgoing — in fact he is after a flat rejection of all contradictions. Thus I guess he can reasonably be argued to assume a rule of logical equity, to treat equal cases equally. If the contradictory nature of contradictions does not debar them from truly applying to $X$, then - no stronger impediment being to be found - nothing prevents them from also applying to any and every other being.

Thus Aristotle believes he has proved that upon AP all is utterly indeterminate and there exists only one (indeterminate) entity.

Aristotle is so overwhelmingly concerned with showing the mutual reducibility of noncontradiction and excluded middle that he is going to return to that close relationship once and again in the sequel. In 1008a31ff Aristotle rewords his arguments: the contradictorialist does not say thus or not-thus, but thus-and-not-thus. But then let us apply the principle of excluded middle to what he says: either he is right or he is wrong; if he is right, he who abides by the principle of noncontradiction is wrong and again something has been reached which is unmixedly or unadulteratedly true and whose negation deserves utter rejection, namely the contradictorialist's own claim. But then (Aristotle is clearly applying Clavius, i.e. that, if $\mathrm{p}$ implies not-p, then not-p) the contradictorialist's claim entails that not all contradictions are true.

Q.e.d.? Well,... yes upon the purported principle of logical equity (plus the purported fact that no obstacle can stand in the way of a contradiction if the mere fact that it is one fails to do so, since it is the strongest obstacle and, when the strongest obstacle is powerless, so is bound to be any other obstacle).

Yet, Aristotle is still patient enough to grant to the contradictorialist an apparently minor point (1008b5-7), namely: perhaps the contradictorialist does not want to claim that what he is asserting is alone true whereas what his adversary says is fully and unqualifiedly false; maybe he is content with claiming that his own view is truer. However - Aristotle goes on to argue - the contradictorialist is thus undermining his own case, since he is claiming that his views are definitely truer; hence something is only-true, namely that the degree of truth of the contradictorialist claim is higher than the degree of truth of the opposite claim. If again the contradictorialist challenges that definite watershed and tergiversates by saying that he is not presuming to be definitely more in the truth than his adversary but only that his being more in the truth than his adversary is truer than the opposite claim, then a vicious infinite regress is triggered.

(The foregoing argument is not explicitly developed by Aristotle, but he puts forward the $2 \mathrm{~d}$ step, viz that of recording the fact that, if the contradictorialist is more in the truth 
than his adversary, then there is at least a proposition which must be true to the exclusion of its negation. Climbing up to further steps in the argument and showing how the thus triggered chain is vicious is a common Aristotelian practice, many examples of which are

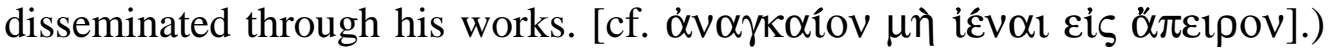

But now we have reached a new stage in the argument. Around «more» and «less» an important branch of the discussion is going to arise. Aristotle is blaming his opponent for a failure to understand that there are degrees in many properties. That reproach may sound odd, since it is often admitted that graduality may be - mistakenly perhaps - suspected to be fraught with contradictory results, esp. when it applies to truth or reality. If some things are more real than others, then there seems to be a fringe wherein opposites co-exist, and for opposites to co-exist in one subject seems to entail that there is a contradictory truth.

As we'll see later on, such a suspicion is really founded and indeed right, so much so that Aristotle's crusade against the hypothesis of contradictory truths is in the end unsuccessful. But for the time being, Aristotle may be credited with a very sly move, trying to show that what - at first blush - seemed to imply true contradictions is in fact incompatible with the contradictorialist claim.

In $1008 \mathrm{~b} 32$ Aristotle starts that new phase of his argument against the contradictorialist. The latter needs to claim exclusive truth for his view - to the exclusion of his opponent's - or at least for a weaker contention, viz that his views ar truer than those of his opponent. What if the contradictorialist has nothing of it and insists that all contradictions are true to

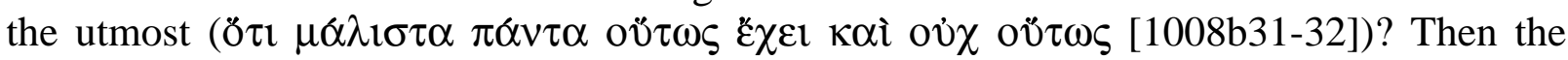
contradictorialist is attacking a common-sensical truism, namely that there are degrees, «that

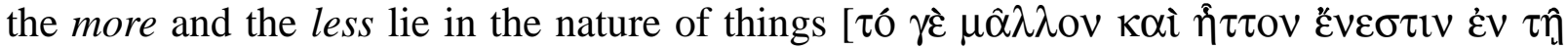
$\varphi \tilde{\sigma \varepsilon l} \tau \hat{\omega} \nu \tilde{\partial v} \tau \omega \nu]$. For one thing, there are degrees of falseness or wrongness; an extreme case is an opinion which deserves to be regarded as wholly false, such as that two is an odd number. Even should we be prepared to swallow the idea that number two is odd and not odd and that so is number three, even then at the very least we'd staunchly cleave to the unnegotiable last trench that number 3 is more odd than number 2, and that he who says that 3 is odd is less wrong than he who claims that 2 is odd. If even as regards such extreme situations degrees apply - if only degenerately — , they clearly apply, too, to more common cases (1008b34-1009a5). He who, speaking of a set of four members, mistakenly claims that it has five members errs less than he who says that it has one thousand members (the latter being wider from the truth). Hence there are degrees of distortion of reality (erroneousness or falsity). ${ }^{12}$ If there are degrees of falseness, there are degrees of truth, too. But if there are degrees of truth, that alone ruins the thoroughgoing contradictorialist claim that all assertions are equally true (and false) — since, according to that claim, for every «p» and «q», that $\mathrm{p}$ is truer than $\mathrm{q}$ would supposedly be true and not true, and so on and so forth. Moreover, if there are degrees of truth it seems extremely likely (1009a2-3) that there is something which is fully or entirely true, a pure truth to which partial or diminished truths are but approximations. Needless to say, such a complete, whole truth would be true to the total exclusion of its opposite, which would be thoroughly and only false.

\footnotetext{
12. However in Cat. VI (6a20-27) quantities are portrayed as not admitting of degrees: one thing cannot possibly be 2-cubits-long in a higher degree than another; nor can a triad be more of a three than a quintet or five-tuple. No such gradation is possible.
} 
Once those results have been reached, Aristotle launches a side-attack on such philosophers as have begged to disagree on those issues [1009a6ff], uprooting and dispelling the causes of their confusion. He names names. Besides Protagoras, Anaxagoras, Democritus and Empedocles are charged with such «Heraclitizing» confusions 'and so to speak everybody else [among past philosophers] embraced such a view': 1009b16-17). Anaxagoras and Democritus thought that opposite properties co-exist in the same subject. The former believes that all is mixed, while the latter thinks that Being and Not-Being (the full and the empty) are everywhere present together. Even Parmenides is charged with having concurred (1009b21ff), at least as regards the basic confusion, namely mistaking appearance for truth. Well, Aristotle probably is not serious about that charge against the founder of the Eleatic school, and he only means to say that a clear distinction between truth or reality and appearance is needed unless contradictory results are going to be endorsed (and Parmenides himself thinks that, were the physical world of variegated and multi-entity nature to exist, it would be contradictory; his disagreement with Heraclitus, Anaxagoras, Democritus and Empedocles consisting only in his denial of the reality of variegated nature).

After a very long digression which does not concern us here, Aristotle comes back to the problem of the mixture of opposite properties at 1011b13ff. We have just seen how, appearances to the contrary notwithstanding, the very same fact that we need 'more' and 'less' constitutes - according to Aristotle - a powerful reason to at least reject the view that all contradictions are true, and hence Anaxagoras' mixture ontology which Aristotle regards as being committed to the acceptance of all contradictions as true.

But what is really going on? What does Aristotle feel he is thereby establishing? Just that not all things are mixed? That it is not the case that there is sand in blood, and blood in sand, and bone in wine, and wine in air and so on - since purportedly then all things would be equally so-and-so, all things would be alike, with no difference being made allowance for, not even one of degree? No, Aristotle feels entitled to draw a far stronger conclusion, namely that no two opposite properties stand in the same subject - ever! Why so?

Aristotle advances the following reasoning (1011b17-24): out of any two contrary properties, one of them is a negation of the other ( $\sigma \tau \varepsilon \rho \eta \sigma ı \varsigma$ [privation, lack], $\alpha \pi \delta \varphi \alpha \sigma \imath \varsigma)$; then if two contrary properties are to be found together in one subject, to the subject in question two contrary predicates could be truthfully applied, which purportedly runs against the attained result. Yet what is that result in fact? Aristotle is clearly assuming that it is a rejection of

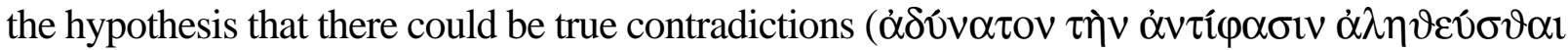
$\kappa \alpha \tau \grave{\alpha} \tau 0 \hat{v} \alpha \hat{\tau} \tau 0 \hat{})$. However Aristotle is clearly overstretching the scope of what he is entitled to claim he has established. Either by the time he reaches this closing part of the discussion (the last pages of Book $\Gamma$, or IV) he has lost the thread of his own reasoning or what he presumes to have proved allows him to jump to this thoroughgoing rejection of all contradictions.

In fact the latter alternative seems more likely. Aristotle may clearly assume to have established that not all contradictions are true - or even that not all contradictions about a given subject are true. Then no contradiction is true (in any degree). Why? Aristotle is silent on the reason, but quite probably the missing link is the principle of logical equity: to treat like cases alike. Let us recall how Aristotle was invoking PN before: if for X, an A, to be an $\mathrm{A}$ is not an obstacle strong enough to prevent it from also being a non- $\mathrm{A}$, then $\mathrm{X}$ is $a$ 
fortiori a non-B, non- $\mathrm{C}$, etc. In the same vein Aristotle clearly seems to assume that, if a pair of assertions, «p» and «not-p», can be true, if the mere fact that $\mathrm{p}$ is true is not a sufficiently strong obstacle to prevent not-p from being true, then nothing can stand in the way of not-q being true when $\mathrm{p}$ is true, the same applying to any statement «q» whatsoever.

The inference seems to be so straightforward and obvious to Aristotle that it is left untold. Doubtless he takes it for granted that, if the rule of avoidance of contradictions does not validly hold, nothing can stand in the way of a contradiction being true - whatever the particular content of the involved assertion and its respective denial. Again apply the principle (or the rule) of logical equity: if the rule of rejection of contradictions is powerless to stem a certain contradiction «p-and-not-p» from being true, the floodgates are open; a weaker (or more qualified) principle cannot do what a stronger principle is powerless to do. Albeit there is a certain amount of guesswork in the foregoing paragraphs, one thing is certain: Aristotle jumps as an immediate, evident, indisputable inference, from the claim - he can presume to have established - that not all contradictions are true to the claim that no contradiction is true. Only a very strong, plausible and apparently unproblematic principle can justify such a jump. The principle of logical equity enjoys those features. And Aristotle is clearly committed to that principle in a lot of passages.

The only hitch is that the principle of logical equity or fairness does not countenance the claim that the job a stronger principle cannot do a weaker principle cannot do either. For one thing, the reason why the stronger principle fails to fulfil the task may be, not that it is powerless to do the job, or that the job is too heavy as compared with the principle's potency, but because the principle is false; were it true, it could do the job - and was Don Quixote an existing knight, he would protect many an unfortunate maid. It does not follow that people less strong (bodily or morally) than Don Quixote cannot defend oppressed lasses. Likewise, even if the rule of rejection of contradictions fails to stifle a certain, particular, true contradiction, the reason may be, not that the rule is powerless, but that it is not correct, that reality does not abide by such an unconstrained, unqualified rule. But other, more modest, more restricted rules may be able to perform the task of preventing certain contradictions (not all contradictions); rules which attend either to the «content» or to the «form» of the contradictions in question - not only to the mere fact that they are contradictions, but to specific and characteristic features of different sorts or classes of contradictions.

And now the sorry end. Aristotle has alleged that the contradictorialist claim is refuted by the acceptance of degrees, of situations of more and less so-and-so. He has ascribed a major role to the recognition of degrees in his argumentation. But now, when he reaches the end of the discussion in Book IV, his plight looks grim: while trying to infer from the rejection of contradictions that opposite properties cannot stand in the same subject and that nothing can be in-between being-so and not-being-so, he enters an impasse: there is no way of accounting for degrees without the coexistence of opposite properties in the same subject. Perhaps he somehow - if dimly — realizes as much — and rather than carrying the discussion forward, he suddenly breaks it up. Yet the problem arises again in sundry passages of his works - never to reach a clear or convincing solution.

Upon briefly drawing from his rejection of any contradictorialist claim the conclusion that contrary properties can never be in the same subject, at least not $\dot{\alpha} \pi \lambda \hat{\omega} \varsigma$ ( $\dot{\alpha} \delta \tilde{v} \alpha \tau \sigma \mathrm{v}$

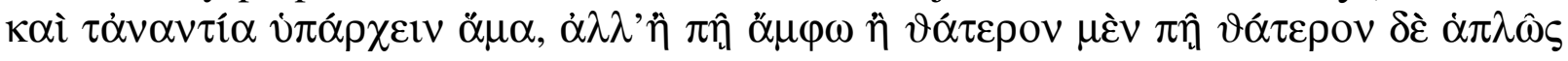


- i.e. at most one of the coexistent contrary properties can be unqualifiedly present, while at least one of them, if present at all, must be present $\pi \hat{\eta}$ [somehow, in a certain way — or perhaps to some extent]), Aristotle goes on (10011b23ff) to argue that no situation can exist in between the presence of a property and that of its contradictory one (i.e. its complement):

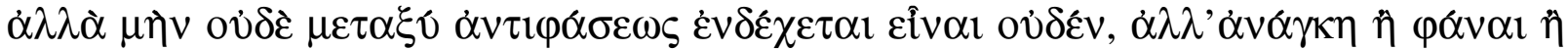

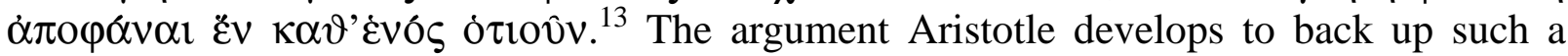
rejection of the Anaxagorean $\mu \varepsilon \tau \alpha \xi \tilde{v}$ (In-Between) uses his well-known definition of truth: to say of what is that it is and to say of what is not that it is not, that is saying the truth (speaking truthfully); to say of what is that it is not, or conversely, that is to say a falsity.

But in the preceding lines - to which we have referred a couple of paragraphs back - , when defending his view that contrary properties cannot coexist in the same subject at least not unqualifiedly - , Aristotle has just pinpointed what surely is the main reason why such a coexistence cannot be realized, namely that out of two contrary properties one of them is the lack of the other (lack, privation - $\sigma \tau \varepsilon \rho \eta \sigma ا \varsigma)$. A detailed analysis of Aristotle's view of privations or lacks as entia rationis goes beyond the scope of this paper. Anyway, Aristotle is surely not implying that out of any two contrary properties one of them is just a mere lack of the other, the latter being the only positive or real property. Admittedly he emphasized

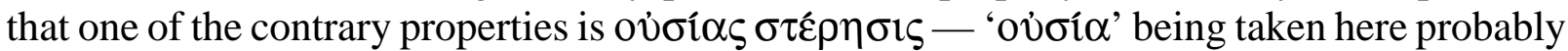
not in its Aristotelian technical sense, but as a loose synonym of 'being', 'reality'. Now, either Aristotle is in this passage taking ' $\tau \dot{\alpha} v \alpha \nu \tau i ́ \alpha$ ' as meaning not the opposites or contrary properties, but more particularly the contradictories - which is possible — or else what alone he is assuredly trying to say is that out of two opposite (or contrary) properties one of them carries the negation (the absence, the lack, the privation) of the other. (For instance, redness is not a mere lack of blueness, but it carries - in a loose sense, «is» - a lack of blueness.)

Now, when turning to face the Anaxagorean In-Between, Aristotle argues that such a $\mu \varepsilon \tau \alpha \xi \tilde{v}$ would lie in-between being and not-being (since we've just seen that the presence of a property is [a] being, its absence a non-being, and that two opposite properties cannot coexist in the same subject since that would entail the presence-and-absence of a property in the subject under consideration). The «in-between» would be in-between yes and no, presence and not-presence, and hence in-between truth and falsity. Aristotle shows that such a third situation would in fact be an impossible coexistence of opposites in the same subject.

Indeed, either the third situation under review would be an entirely irreducible property, so to speak as a heterogeneous kind in-between man and horse, or else it will be related to the extremes as grey is in-between black and white (1011b31). The former hypothesis would be absurd, since then there would be a third irreducible property, $X$, in-between white and not-white, and a thing could be whitened (become white) not only from being not-white, but also from being $\mathrm{X}$. But surely to become white is to lose non-whiteness and nothing else, not to lose either non-whiteness or a mysterious $\mathrm{X}$.

\footnotetext{
13. In book V of Metaphysics, ch. 10 (1018a25-26), Aristotle defines 'contraries' as such properties as cannot coexist in the same subject:

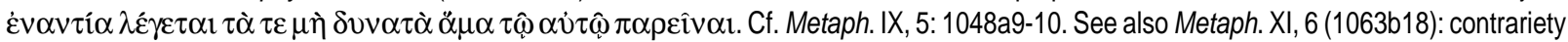
implies privation; see also Metaph. X, 5 (1055b23-27). There, for once, Aristotle suggests that, whereas such numbers as are even are not odd at all, with no number being inbetween complete oddness and complete evenness - and that in such cases every lack of one of the contraries is complete -, in other cases there is something in-between complete X-ness and complete not-X-ness.
} 
Aristotle has thus shown that, supposing it exits, the intermediary situation (the inbetween) must be like grey in-between black and white. Unfortunately though he does not tackle this alternative squarely, but the context clearly conveys this message: since grey would be a mixture of black and white, and hence - as we have just seen - of white and not-white, which, being opposites, cannot coexist in the same subject, nothing is grey simpliciter (unqualifiedly). There is nothing such as greyness - at least not simpliciter.

Such a startling conclusion may have startled even Aristotle, who in fact does not state it in so many words. Yet the sequel of the argument amounts to an implicit avowal of such views; 1012a9ff: if such an intermediary situation exists about a certain property, the same can happen with any other property (in virtue of the principle of logical equity); and there will be infinitely many such situations: in-between black and white, grey or black-andwhite; in-between grey and white something will be both black-and-white and white; and so on. Thus (1012a27-29) Anaxagoras was as wrong as Heraclitus: opposites do not mix, since the mixture would lie in-between the opposites; the mixture would be neither god nor not-god, neither white nor not-white. Thus Anaxagoras has reached the same views as Heraclitus did through a different path. Asserting mixtures of opposites — and hence negations of instances of excluded middle - amounts to asserting contradictions.

\section{§3.- Aristotle’s Quandary Concerning Degrees and Intermediaries}

We have seen that in 1008b5 and 1008b31-34 Aristotle argues against the contradictorialist that even if - per impossibile - all contradictions were true and accordingly all statements were truthfully assertible, some statements would have to be truer than others; but then some statements must be definitely, unmixedly true (those to the effect that some statements are truer than others), unless a vicious regress is triggered. Therefore not all statements are true. Therefore not all contradictions are true. Therefore - in virtue of the principle of logical equity - no contradiction is true. And thus, finally, no contrary properties co-exist in the same subject. Therefore, in-between the presence of a given property $\mathrm{P}$ and that of its contradictory property non-P in a given subject $\mathrm{S}$ there is no possible third or intermediary situation. There can be no state of merging, mingling or coalescence of opposites. Thus if grey exists it cannot be an amalgamation or combination or mixture of black and white (or of black and non-black, or white and non-white). Nor can it be a heterogeneous irreducible tertium quid.

Is Aristotle claiming that grey does not exist, that degrees do not exist, that nothing can be whiter (or prettier, or cleaner, or stronger or ...) than another thing? He obviously does not want to be committed to such a rejection. But whether he wants it or not, and bitter though the commitment may be, the last part of the argument in Book $\Gamma$ - especially his attack on Anaxagorean In-Betweenness - deprives him of the right to recognize degrees.

Aristotle is often wavering on degrees of truth. In some passages he clearly espouses their existence, while there are good reasons for him to avoid committing himself to degrees of falseness. ${ }^{14}$ However it is impossible to implement a convincing account of degrees of anything without degrees of truth, and one of degrees of truth without degrees of falseness;

14. I'll come back to this issue below. 
if and only if $\mathrm{X}$ is whiter than $\mathrm{Z}$ the statement ' $\mathrm{X}$ is white' is truer than the statement ' $\mathrm{Z}$ is white'. Be it as it may, the difficulty about degrees arises whether or not one tries to make allowance for degrees of truth specifically — rather than degrees in general.

There are two possible ways only of understanding the existence of degrees. One is admitting the coexistence of opposite properties in the same subject and admitting that a property may be more and less present; thus white and black would co-exist or blend in grey objects, with certain objects being whiter than others owing to the fact that whiteness is more present in the former and blackness is less present - or that the former have more whiteness and less blackness than the latter: the more whiteness an object contains, the less blackness it has.

The alternative explanation is that grey — and, what is more, each hue or shade of grey - is an irreducible tertium quid. The only reason why we could still talk of degrees would be the existence of a certain scale which would then be required to be overimposed on the concerned series (or rather set) of properties. It would be stipulated that Grey ${ }_{1}$ would be whiter than $\mathrm{Grey}_{2}$, and so on, but as to why those different hues of grey are grouped together in the kind grey and why each is given a particular index, no explanation would be available. Either an arbitrary convention or an equally arbitrary Fiat of mother nature would be fallen back on.

Since the latter proposal is clearly unsatisfactory, Aristotle consistently tries to keep clear of such a view. Unfortunately though the other alternative is closed to him, in virtue of his rejection of the possibility of a co-existence of opposite properties in the same subject.

Sometimes Aristotle implies that, when an entity acquires an ever so small degree of X-ness, it thereby becomes $\mathrm{X}$ and thus its further reaching a higher degree of $\mathrm{X}$-ness is not a transition from not-X-ness to X-ness, but only a change through which what was already $\mathrm{X}$ becomes X-er (Phys. 9: 217a29-217b9). In other words: only what is already hot can become

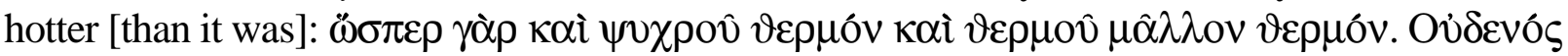

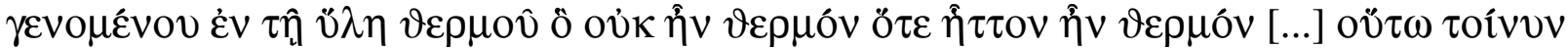

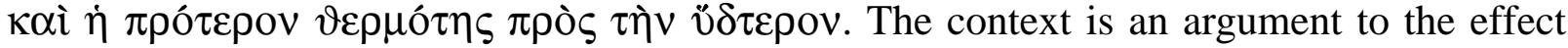
that $v ं \lambda \eta$, or matter, is indifferent towards contraries, and a common underlying receptacle for them (alternatively, not simultaneously). Thus nonprime matter, i.e. a substance, when it is cold, can lose its accident of coldness and acquire the accident of heat. Once it has become hot, it can, without losing that accident, become hotter; in that case the accident gets intensified (enhanced, heightened). The difference between a higher and a lower degree of heat is said to be like the difference between coldness and hotness. The likeness in question ( $̋ \sigma \pi \varepsilon \rho$ o $\tau \tau \omega)$ ought to be qualified: whereas in the one case an accident is dropped and its opposite enters the subject, in the latter case the accident is kept, and what alone is lost is a curtailment or limitation of degree: more of the accident accrues to the subject, but the latter was already there. The obvious difficulty with such a view is that a body can be somewhat cold and somewhat hot, which, in accordance with the just considered account, would mean that is is both cold and hot, and therefore both cold and non-cold - coldness and hotness would coexist in that body.

Aristotle could still save his enterprise by resorting to a desperate move. First, he needs to waive degrees altogether as his own philosophical views are concerned. The 'more' and the 'less' would belong in the pre-scientific or vulgar way of speaking. Once scientific 
concepts are adopted, things are definitely and unmixedly so-and-so or else definitely and unmixedly not so-and-so, neither more nor less so-and-so than others. The second part of the move would consist in claiming that degree-talk in 1008b5 and 1008b31-34 was purely for the sake of the argument, or an ad hominem device: if the Heraclitean claims - as Aristotle for one thinks he claims or at least is committed to claim - that all sentences are true, then in order to convey a meaningful message, he would doubtlessly maintain that his views are truer than those of his opponents, since otherwise he wouldn't be entitled to dispute his opponent's views or to disagree with them. Thus it is the contradictorialist himself who would need to resort to truth-degrees — which purportedly he cannot do according to Aristotle's lights.

Although such a construal is clearly not in accordance with the plain sense of the passages analyzed above [1008b5 through 1008b34] (wherein Aristotle is clearly advocating degrees, even degrees of truth, as a plausible view, not as an arguing trick), as a safe retreat Aristotle could, even if grudgingly, resign himself to the sacrifice. The problem is that then the anti-Heraclitean objection becomes quite dubious. To start with neither Heraclitus nor any other among the philosophers Aristotle targets (except Protagoras) is likely to have believed that all statements (or all contradictions for that matter) are true. Supposing a philosopher was foolish enough to think that all statements are true, he would not be deflected from that course of thought by the objection that he lacks any rejection criterion. He would need no such criterion, since he would reject nothing. Nor would he disagree with anyone - even if other people would say they disagree with him, even then what they would say would be right [and also wrong], and he himself would have no reason to reject their claims.

Degrees of truth are hesitatingly espoused by Aristotle. In the passage of Metaphysics IX, 5 [1008b33-1009a1] he claims that he who asserts the less wrong claim $\mu \hat{\alpha} \lambda \lambda$ ov $\dot{\alpha} \lambda \eta \vartheta \varepsilon v ́ \varepsilon 1$ - is more in the truth, i.e. what he says is truer. The idea is clear: there are couples of claims, $\mathrm{C}_{1}, \mathrm{C}_{2}$, lying in-between pure or entire truth and utter or complete falsity, such that $\mathrm{C}_{1}$ is truer than $\mathrm{C}_{2}, \mathrm{C}_{2}$ being falser than $\mathrm{C}_{1}$. We would say that in each of them there is truth and there is falsity. But then there are as many degrees of falsity as there are degrees of truth minus one (the fully true), and conversely; and a non-full degree of truth is also (or at least is necessarily accompanied by) a degree of falseness.

But the only way of elucidating such an intertwining of degrees of truth and degrees of falseness would be to accept the co-existence of contrary properties in the same subject, ${ }^{15}$ which, as a rule, Aristotle refuses to do. ${ }^{16}$ Thus, once and again, he comes back to one of his favourite objections against any Heraclitizer, namely (Metaph. XI, 5: 1062a22ff.): if you say that $\mathrm{X}$ is $\mathrm{A}$-and-not-A, you are in effect claiming that $\mathrm{X}$ is no more $\mathrm{A}$ than not-A $(\mu \eta \delta \varepsilon v$

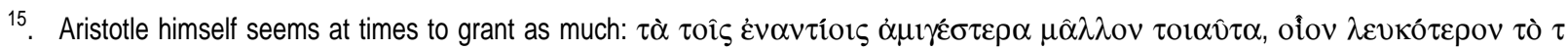
$\hat{Q} \mu \varepsilon \hat{\varepsilon} \alpha \nu \imath \dot{\alpha} \mu \gamma \gamma \varepsilon \tilde{\varepsilon} \tau \rho \rho v$ : the less a thing is mingled with its contrary, the more it is what it is, and thus whatever is less mingled with black is whiter (Topics III, 5 [119a27-8]).

16. The emphatic rejection of the hypothesis of a coexistence of opposite properties in the same subject is repeated once and again in the Aristotelian corpus (even if at times Aristotle seems to suggest a perhaps half-hearted or reckless admission of such a coexistence); see e.g.

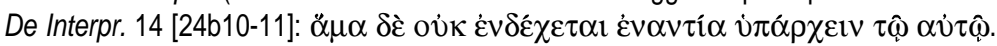




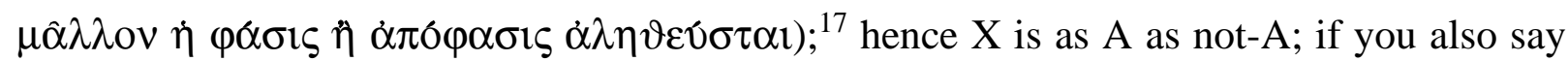
that $\mathrm{Y}$ is and is not $\mathrm{A}$, you again imply that $\mathrm{Y}$ is neither more nor less $\mathrm{A}$ than not- $\mathrm{A}$. Hence $\mathrm{X}$ is as $\mathrm{A}$ (and as not- $\mathrm{A}$ ) as $\mathrm{Y}$ is (since they have the same degree of $\mathrm{A}$-ness, one which is exactly equidistant between the extremes of $\mathrm{A}$ and not-A).

Intermediary claims (like $\mathrm{C}_{1}, \mathrm{C}_{2}$ ) which are neither entirely true nor altogether false must have some alethic quality or other: either truth, or falsity or neither or both. Aristotle argues that to have neither is to have both (whence Anaxagoras' views are reduced to a variety of Heracliteanism). Then, either both $\mathrm{C}_{1}$ and $\mathrm{C}_{2}$ are true, or they are both false, or one of them is true and the other false. But Aristotle's own frequent examples show that an infinite regress can be triggered (in virtue of the existence of potential infinities). Thus, if there are alethic intermediaries, there is a convenient choice for $\langle i, j\rangle$ such that $C_{i}$ and $C_{j}$ should be in the same boat (i.e. both true, or both false or both true-and-false): either the falser claim is still true, or the truer claim is still false.

Now, in accordance with Aristotle's own canons for comparatives (see Topics II, xi: 115b4-8), if anything is predicated in a higher or lower degree, it is also predicated tout court $(\dot{\alpha} \pi \lambda \hat{\omega} \varsigma)$ : only a white thing is whiter, or less white, than another thing. ${ }^{18}$ Thus, if a claim $C_{i}$ is truer than $C_{j}$, they both are bound to be true. But, if $C_{i}$ is truer than $C_{j}$, there shall be more falseness in $\mathrm{C}_{\mathrm{j}}$ than in $\mathrm{C}_{\mathrm{i}}$. Thus they must be both false too!

Yet Aristotle thinks that something can be asserted $\dot{\alpha} \pi \lambda \hat{\omega} \varsigma$ (tout court, or unqualifiedly) only when it is $\varepsilon i \lambda \iota \kappa \rho \imath \omega \hat{\sigma} \varsigma \dot{\alpha} \lambda \eta \vartheta \varepsilon \varsigma: 1009 \mathrm{a} 3 .{ }^{19}$ (That is why Anaxagoras' views imply that — since all stuffs are reportedly mingled or blended — nothing has any property ( $\varepsilon i \lambda \imath \kappa \rho \imath v \hat{\omega}$

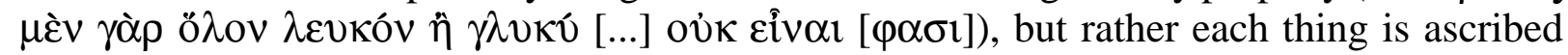
the predicate which properly applies to the stuff it mostly contains (Phys. 4: 187b4-7).) We have seen that in Met. $\Gamma$ [1008b] Aristotle claims in effect that a statement which is truer

\footnotetext{
17. Aristotle labours under a confusion around the two senses of the Greek phrase ' $\mu \alpha \hat{\alpha} \lambda \mathrm{ov} \eta \eta^{\prime}$ ', which resembles the English one 'rather than':

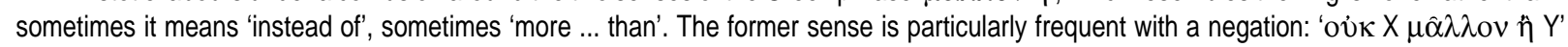
often means 'not X rather than [i.e. instead of] Y'. (See Kirk, Raven \& Schofield, op. cit., p. 411; see also «Aporetic Pyrrhonism» by Paul Woodruff, Oxford Studies in Ancient Philosophy, vol. 6 (1988), pp. 139ff, with a discussion on the formula "ou mâllon» in Aenesidemus and in Plato. Cf Rep 479a6-7: ta pollá kalá are no more beautiful than ugly — surely in the sense, not that they are exactly as ugly as they are beautiful, but that they are not uniquely ugly without any admixture of beauty or the other way round.) Also Aristotle in Metaph. $\Gamma 5,1009 \mathrm{~b} 10-11$ : o o $\delta \dot{\varepsilon v}$

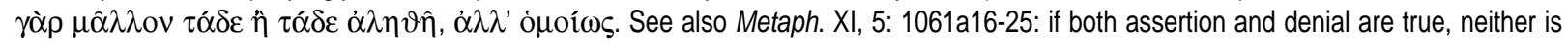
truer than the other (or nothing is [uniquely] true rather than its opposite), and so nothing has been truthfully said.
}

18. See also Topics II, 11 (115a25ff): if something, $X$, upon being added to another thing, makes it either white or whiter than it was, then $X$ is white. Now, an almost white grey when added to a somewhat darker grey makes it whiter than it was. Thus light grey is white - a conclusion which of course runs against Aristotle's repeated claim that grey is neither white nor black. See also Cat. V (4a4): white things can become whiter, or less white than they were, while remaining white, whereas a non-white entity can become white, but cannot become whiter (or less white) than another thing. Obviously Aristotle's views are fraught with an unsurmountable difficulty: suppose a thing, X, is less white than Z; then, to be sure, $X$ cannot be fully white. Hence, in accordance with Aristotle's principle (see next paragraph and next note) that only what is wholly or unmixedly true is true, $X$ is $\dot{\alpha} \pi \lambda \hat{\omega} \varsigma$ (unqualifiedly, tout court) not white. But again in virtue of the same principle, $X$ will be entirely non-white, and therefore nothing can be less white than $X$. On the other hand, since $X$ is not white, it cannot be said to be either whiter or less white than any other thing!

19. Accordingly, only what is completly or fully hot can be (unqualifiedly) said to be hot. Thus, when a thing is colder (or less hot) than another, the former is not hot, even if - in accordance with In Gen. Et Corr. 2,7 (334b8-14) - something can be $\omega \varsigma \mu \varepsilon v \vartheta \varepsilon \rho \mu \delta v \psi v \chi \rho \delta \nu, \dot{\omega} \varsigma \delta \varepsilon$

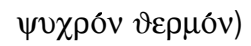


than another is closer to a true statement - i.e. to a statement which is simply true, which Aristotle obviously identifies with being completely true). ${ }^{20}$

In Topics IV (123b) the Stagirite claims that the negations of both contraries apply

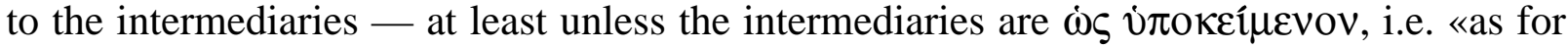
the subject, or receptacle», which is a cryptic remark.

If we join all those claims (namely: (1) that, when a thing is whiter, or even less white, than another, it is white; (2) that what is white is white $\dot{\alpha} \pi \lambda \hat{\omega} s$, and hence white without the slightest degree of non-whiteness; (3) that what is in-between white and black is neither white nor black; and (4) that among intermediaries between black and white some of them are whiter than others), the obvious, glaring result is a flat, downright contradiction. But Aristotle cannot deal with that contradiction in an Anaxagorean way (by resorting to a mingling of being and nonbeing or the like), since is is precisely such an account he is at pains to discredit. $^{21}$

\section{§4.- Rejection and Denial; Admissible vs Inadmissible Contradictions}

Whether or not a Protagorean (most likely not Heraclitean, still less Anaxagorean) view according to which everything is true is to be found congenial or not (and neither the author nor most probably any reader of this paper will like it), Aristotle's resorting to degrees and comparative talk as a refutation device against such views fails. On the other hand, the device would succeed to convince a more moderate contradictorialist, one who claims that some contradictions are true (no all contradictions). Yet, the argument would in any case convince him of what he is already willingly granting. On the other hand, a moderate contradictorialist would clearly reject Aristotle's way of resorting to the principle of logical equity, for reasons already canvassed (what a strong but false principle is unable to avoid, on account of its falseness, a less strong but true principle can effectively prevent, on account of its truth; in the same way, what prevents some people from reaching an age of 80 years is not that people cannot reach such an age, but particular and specific circumstances).

What is required in order to have a theory admitting some contradictions but not all contradictions is a distinction between denial and rejection. For if you believe that a certain contradiction «p and not-p» is true, you — let us assume - believe «p» and also believe «not$\mathrm{p} »$. The latter belief entails that you deny «p», i.e. you assert a negation of «p». Yet you obviously don't reject «p». On the other hand there are many contradictions «q and not-q» you are indeed bent on keeping clear of. In fact denying a statement is in general neither a necessary nor a sufficient condition for rejection. Intuitionists do not deny the principle of excluded middle but they reject it. Somebody who believes in true contradictions does not reject the conjuncts which form those contradictions but denies them.

\footnotetext{
20. In Topics II, 11 (115b30-31) the truth, or being, $\dot{\alpha} \pi \lambda \omega \varsigma$ is defined as that which can be asserted without qualification (for $X$ to be $\dot{\alpha} \pi \lambda \hat{\omega} \varsigma$, or unqualifiedly, so-and-so is for it to be the case that, without any additional phrase, you can truthfully say ' $X$ is so-and-so').

21. Aristotle seems to suffer from a confusion between semantic and pragmatic considerations: the sentence ' $p$ ' $=$ ' $X$ is less $A$ than $Z$ ' may be unusual, pragmatically inappropriate in most contexts, or whatever, while being true. For either ' $p$ ' is true, or it is false; if it is false, it is not the case that $X$ is less $A$ than $Z$; is then $Z$ less $A$ than $X$ ? Are $X$ and $Z$ equally $A$, or equally non- $A$ (i.e. is $X$ as $A$ as $Z$ )? Or none of those situations obtains? Surely either $X$ is more $A$ than $Z$ or $X$ is less $A$ than $Z$ or $X$ and $Z$ are equally $A$ or they are equally non- $A$ (principle of the four alternatives).
} 
Admittedly the difference between denial and rejection was hard to achieve for Aristotle owing to the Greek wording of «saying that not-p» as «not-saying that p» (in the same way as in English 'does not want to X' means 'wants to not X', and 'must not do it' means 'must refrain from doing it' instead of 'haven't got to do it'). However, even in Greek there are linguistic resources to distinguish rejection and denial. For instance, the adjectives

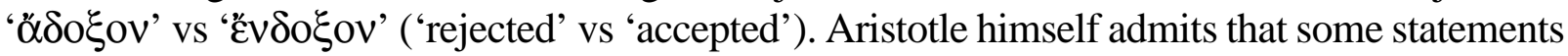
are neither accepted nor rejected, but $\mu \eta \delta \varepsilon \varepsilon \varepsilon \rho o v$ (Topics VIII, 6: 159b39).

Were Aristotle to wonder what non-arbitrary grounds one could offer to know whether a certain denial entails rejection or not — and so as reasons to avoid the explosive spreading of contradictions - a number of such grounds could be offered. One of them - one Aristotle himself seems half aware of at times - is that such properties as admit of degrees can coexist with their respective contradictory properties - to some extent; thus there is a real coalescence of opposites, with the same subject being (partly) white and (partly) non-white. Aristotle himself, while trying to find a reason which would convince the Protagonean contradictorialist, has — at least for a moment — harboured such views.

Another way of differentiating admissible and non-admissible contradictions would be to attend to the words involved: no contradiction is admissible if the involved negation

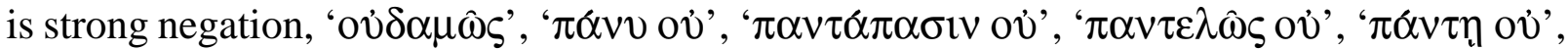
expressions which can be translated into plain English as 'not at all', 'by no means', 'altogether not'. It is not even seldom that Aristotle himself uses such words. ${ }^{22} \mathrm{He}$ apparently does not use them as mere stylistic devices, but in order to convey a certain message which can only be conveyed by using them. Hence, if really those negations - or those different expressions of strong negation - are genuinely different from weak or mere negation, an Anaxagorean can say that no negation is admissible if it involves strong negation. He would not be committed to say of course that all other negations were admissible. For one thing, some negations which are formulated without strong negation would still amount to strong negations on account of the subject matter or of the nature of the terms. For another, the Anaxagorean would not be reasonably expected to provide a detailed or all-purposive criterion to sort out (partly) true contradictions from (entirely) false contradictions. What alone he can be expected to offer is a rejection criterion. And he can claim that a theory is to be rejected if it yields a couple of sentences one of which is the strong negation of the other. For the Anaxagorean is advocating the mixture view of stuffs or properties; hence he admits of intermediaries and rejects the uncompromising (Aristotelian) view according to which, if an object has whiteness, it cannot have non-whiteness at all.

\section{Lorenzo Peña \\ CSIC [Spanish Institute for Advanced Study] Department of Philosophy}

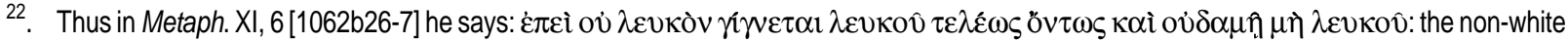
comes to be from what is altogether white and not at all non-white. (Aristotle seems to imply again that all things are either altogether white or else not white at all, surely a very high price to pay in order to avoid true contradictions.) Also in Cat. XII (14b19) Aristotle emphasizes that, even though a man's existence and the truth of the claim that a man exists do necessarily stand or fall together, yet the former causes the latter and nowise (ov̉ $\delta \mu \hat{\omega} \varsigma)$ conversely. A mere 'not' would not have conveyed a thorough, complete denial (it would be compatible with a certain degree of mutual causation). Thus Aristotle cleverly sifts out strong from weak negation whenever it is crucial for dinning in a full, thorough, rejecting denial to his readers.
} 